\title{
レーダ雨量計を用いた洪水位の短時間予湘 \\ Short-Term Forecasting for Water Level of a Flood by Radar Hyetometer
}

\author{
九州大学工学部 森 山 䎾 之 Toshiyuki MORIYAMA \\ 九州大学工学部 平 野 宗 夫 Munei HIRANO \\ (株) 建設技術研究所 中 山 比佐雄 Hisao NAKAYAMA \\ （株）建設技術研究所 松 尾 景 治 keiji MATSUO \\ 九州大学大学院 鐵 谷 浩 之 Hiroyuki TETSUYA
}

\begin{abstract}
Recently, weather radar has been fully utilized and detailed real-time information over a wide range of area has become obtainable with hight time-space resolution. But the accuracy of the radar hyetometer is not always high enough to use for flood forecasting.

In this paper, a forecasting method by using radar data is proposed, in which, a radar constant is included in the system parameters and identified together by Kalman filtering. The application of this method to the Onga river basin shows that the forecasting of water satges by using radar data is possible with the same accuracy of that by rainfall data on the ground.
\end{abstract}

Keywords: flood prediction, radar hyetometer, Kalman filter, kinematic wave theory

1.はじめに

わが国においては、雨量-流量变換系を用いた流出解析や流出予測は盛んに行われさまさまな手法が開発され てきた。しかし雨量データそのものには誤差が多く、そのうえ降雨-流出の変換を行う際には更に多くの誤差が含 まれる。これに対して、水位データは降雨-流出変換後の量であるから、雨量に比しはるかに上質のデータであり． 洪水予測に際しては、極力水位データを利用すべきであると考えられる。このような考えのもとに、前論1)では 地上雨量計のデータを単位四法に適用し、流出デー夕は流水断面積として特性曲線法を適用し、それそれのパラ メタをカルマンフィルターで同定することによって水位を予測する手法を提案し、良好な結果を得た。一方、近 年建設省のレータ雨量計が全国各地に建設され、広い範囲の雨量データを高時に高解像度で求めることが出来る という特徵から、その活用に大きな期待が寄せられている。しかしレーダ雨量計は、レーダ定数の評価に問題が あり、誤差が大きいという問題がある。そこで本詥文ではレーダ反射因子を入力とし、レータ常数を流出パラメ 一タに加えてカルマンフィルターで同時に同定することより、洪水予測を行い、地上雨量計を用いた場合と比較 した。

\section{2. 予測式の誘尊}

河道における連続の式、運動の式は、流量をQ，流水断面積をA，横流入量をq *とすると、それぞれ次のよ うに表すことができる。

$$
\frac{\partial \mathrm{A}}{\partial \mathrm{t}}+\frac{\partial \mathrm{Q}}{\partial \mathrm{x}}=\mathrm{q}_{*}
$$

$$
\mathrm{A}=\mathrm{KQ}{ }^{\mathrm{P}}
$$

ここに、tは時刻、 $\mathrm{x}$ は下流方向に測った距離、 $\mathrm{K}$ とPは定数である。式（1）および（2）を変形して特性曲 線法で解くと次式が得られる。

$$
A_{2}(t)-A_{1}\left(t-\tau_{2,1}\right)=\int_{t-\tau_{2,1}}^{t} q * d t-\int_{t-\tau_{2,1}}^{t} A \frac{\partial K}{\partial x} d t
$$

ここに、添字 1,2 は上流及び下流の水位観測点を示し、て 2 は1 2 地点間の洲水の到達時間である。式（3）右辺第 2項は、次のように近似できる。 
$\int_{\mathrm{t}-\tau, 1}^{\mathrm{t}} \mathrm{A}^{\mathrm{p}} \frac{\partial \mathrm{K}}{\partial \mathrm{x}} \mathrm{dt}=\int_{0}^{\mathrm{L}_{21}} \frac{\mathrm{A}}{\mathrm{KP}} \frac{\partial \mathrm{K}}{\partial \mathrm{x}} \mathrm{dt} \doteq \frac{\mathrm{L}_{21}}{2}\left\{\frac{\mathrm{A}_{2}}{\mathrm{~K}_{2} \mathrm{P}_{2}} \frac{\partial \mathrm{K}_{2}}{\partial \mathrm{x}}+\frac{\mathrm{A}_{1}}{\mathrm{~K}_{1} \mathrm{P}_{1}} \frac{\partial \mathrm{K}_{1}}{\partial \mathrm{x}}\right\}=\mathrm{C}_{1} \mathrm{~A}_{1}\left(\mathrm{t}-\tau_{2,1}\right)+\mathrm{C}_{2} \mathrm{~A}_{2}(\mathrm{t})$

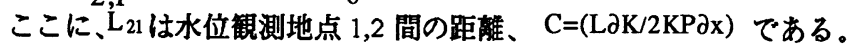

また、 $9 \cdot の$ 算定に単位国法を適用すると

$$
\mathrm{q}_{*}=\int_{0}^{\mathrm{t}-\tau \mathrm{s}}\left[\mathrm{u}(\tau) \mathrm{fr}\left(\mathrm{t}-\tau_{\mathrm{s}}-\tau\right) \mathrm{d} \tau\right.
$$

ここに、泣斜面長、 $\mathrm{f}$ は流出保数、 $\mathrm{u}(\tau)$ は四間単位图および $\tau_{\mathrm{s}}$ は斜面における暒れ時間である。

式 (5) 上り式 (3) の右辺第 1 項忧次のように変形される。

$$
\begin{aligned}
& \int_{t-\tau 21}^{t} \mathrm{q} * \mathrm{dt}=\ell \int_{t-\tau 21}^{\mathrm{t}} \int_{0}^{\mathrm{t}-\tau} 21 \mathrm{u}(\tau) \mathrm{f} r\left(\mathrm{y}-\tau_{\mathrm{s}}-\tau\right) \mathrm{d} \tau \mathrm{dy} \\
& =\ell \sum_{i=t-\tau_{2}, j=0}^{t} \sum_{i=0}^{i-\tau_{s}} f u(j) r\left(i-\tau_{s}-j\right)
\end{aligned}
$$

式（3）に式（4）および式（6）を代入すると、I 時間後の下流側断面積は次式で与えられる。

ここで、

$$
\mathrm{A}_{2}(\mathrm{t}+\mathrm{I})-\mathrm{A}_{2}(\mathrm{t})=\mathrm{k}\left\{\mathrm{A}_{1}\left(\mathrm{t}+\mathrm{I}-\tau_{2,1}\right)-\mathrm{A}_{1}\left(\mathrm{t}-\tau_{2,1}\right)\right\}+\sum_{\mathrm{i}=0}^{\mathrm{t}-\tau_{\mathrm{s}}} \mathrm{U}(\mathrm{i}) \mathrm{R}(\mathrm{i})
$$

$$
\mathrm{k}=\frac{1-\mathrm{C}_{1}}{1+\mathrm{C}_{2}}, \mathrm{U}(\mathrm{i})=\frac{\mathrm{f} \ell}{1+\mathrm{C}_{2}} \mathrm{u}(\mathrm{i}) 、 \mathrm{R}(\mathrm{i})=\sum_{\mathrm{j}=0}^{\tau_{21}}\left\{\mathrm{r}\left(\mathrm{t}+\mathrm{I}-\tau_{21}+\tau_{\mathrm{s}}-\mathrm{i}+\mathrm{j}\right)-\mathrm{r}\left(\mathrm{t}-\tau_{21}+\tau_{\mathrm{s}}-\mathrm{i}+\mathrm{j}\right)\right\}
$$

その際、時刻 $\mathrm{t}+\mathrm{I} \tau_{21}$ までの上流側断面皘データと $\mathrm{t}+\mathrm{I}-\tau_{\mathrm{s}}$ までの降雨データが必要となる。よって洪水到達時間が $\tau_{21} \geq 1$ の埸合には上流側断面穔の予测が不要であり、斜面の暒九時間を $\tau_{\mathrm{s}}=\mathrm{I}$ とおくと降雨の予测が不要となる。

3. レータ雨量計デー夕の適用

レーダ雨量計を使用する場合には、その精度が問題であり、 何らかの補正をすることが望ましい。图1は遠賀川秋松橋 流域 (C. A.=1 $\left.133 \mathrm{k} \mathrm{m}^{2}\right)$ における地上雨量計とレー夕 雨量計による1時間雨量の相関を示したものである。地上 雨量データはレータ雨量データの 1.8 倍程度になっており、

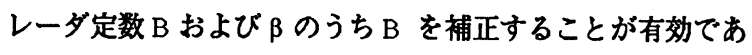
ると思われる。そこでここではの $\beta$ 值を固定し、B の補正 を考える。すなわち（7）式にレーダ雨量計のデー夕を道 用する埸合、レーダの反射因子 $\mathrm{z}(\mathrm{mm} / \mathrm{m})$ と雨量强度 $\mathrm{r}(\mathrm{m}$ $\mathrm{m} / \mathrm{hour})$ との式 $\mathrm{z}=\mathrm{B} \mathrm{r}$ を代入すると (7) 式右边第 2項は次のようになる。

$$
\begin{aligned}
& \sum_{\mathrm{i}=0}^{\mathrm{t}-\tau_{\mathrm{s}}} \mathrm{U}(\mathrm{i}) \mathrm{Z}(\mathrm{i}) \\
& \mathrm{U}(\mathrm{i})=\mathrm{mf} \ell \mathrm{B}^{\frac{1}{\beta}} \mathrm{u}(\mathrm{i}) 、 \mathrm{~m}=\frac{1}{1+\mathrm{C}_{2}}
\end{aligned}
$$

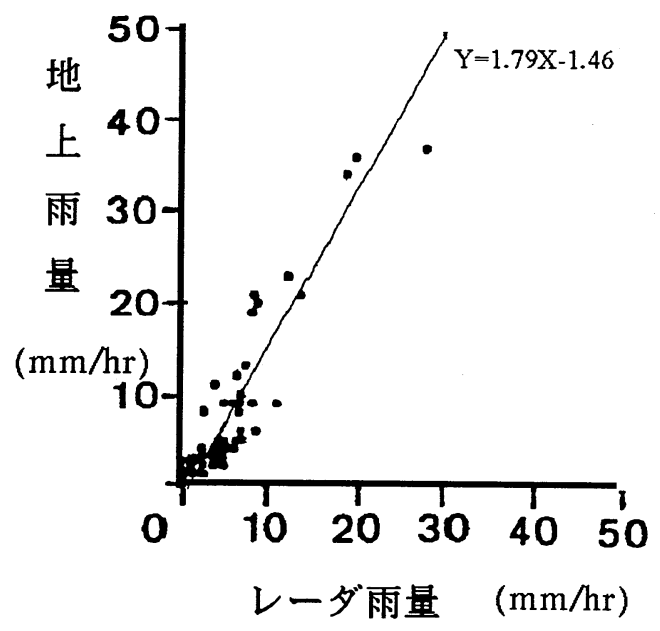

図 1 . 内野 (秋松橋上流) におけ る地上雨量とレーダ雨量の比較 


$$
Z(i)=\sum_{j=0}^{\tau_{2,}}\left[\left\{z\left(t+I-\tau_{2,1}+\tau_{s}-i+j\right)\right\}^{\frac{1}{\beta}}-\left\{z\left(t-\tau_{2,1}+\tau_{s}-i+j\right)\right\}^{\frac{1}{\beta}}\right]
$$

上式はレーダ定数 B が単位図U 中に含まれることを示す。

\section{4. 現地への適用とその結果}

4. 1 適用流域およびデー夕

本予測モテルを福岡県の遠賀川流域に適用し、その実用性を検証する。图2に示すように、水位観測所は、 伊田、春日橋、大涱、秋松橋、川岛、日ノ出橋、宮田橋、中間の 8 ヶ所を対象とし、降雨データとして、地上 雨量に関しては流域内に設西された 13 ヶ所の雨量観測所の時間雨量記録を、レータ雨量に関しては、釈迦岳 に設霆されている建設省九州北部レーダを用いる。レータのの降雨データは、磁気テープに記録された 5 分毎の 生デー夕を使用するが、水位データが 1 時間每であるため、各残流域每に降雨データの 1 時間累計を面積平均 した值を使用するものとする。 なお、予測の対象は流水断面積であり、予測された断面積を水位に変換して 予測水位とする。

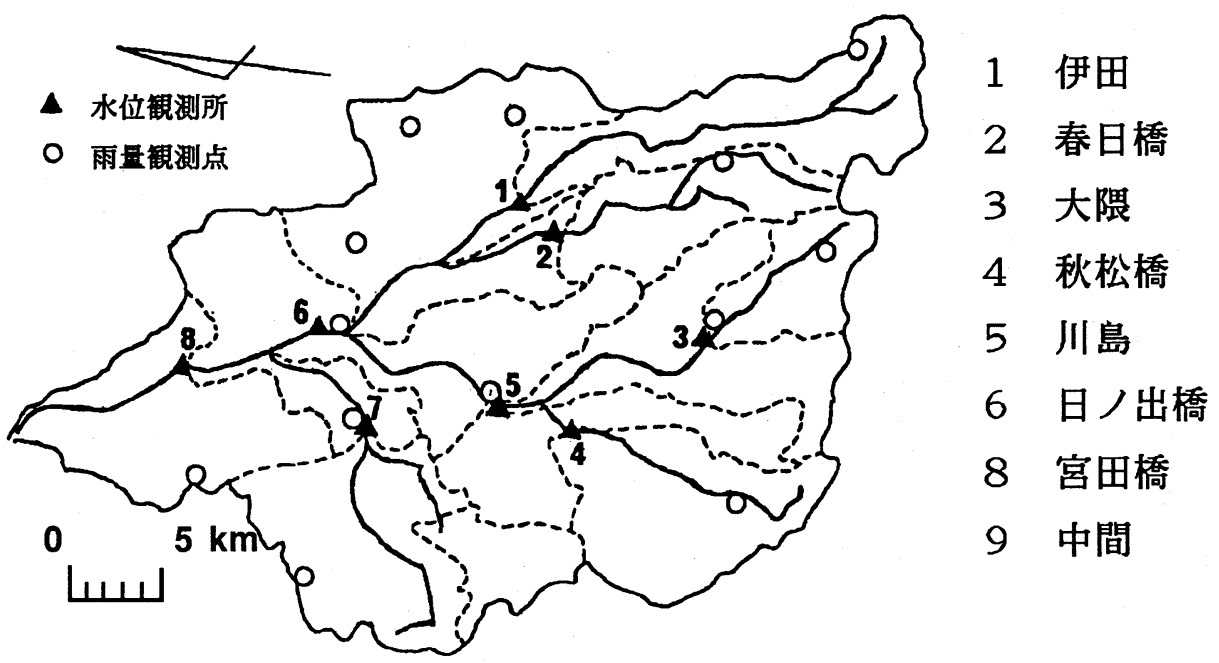

困 2．遠賀川流域分割図

\section{2 レー夕雨量計と地上雨量計による流出予測精度の比較}

まず、レーダ雨量計を用いた場合の精度を地上雨量計を用いた場合のそれと比較するために、最上流域の秋松 橋水位観测所を対象とし予測計算を行った。計算水位と予測水位の比較を图 3 おび图 4 に示す。予測時間は 1 時間である。またそれぞれの計算で得られた最終的な単位图を目 $5 に$ 示す。前述のように、レーダ雨量計と地上 雨量計の観測にはかなりの雨量の差があるにもかかわらず、水位予測の精度はははとんど同程度になっている事 に注目したい。これは図5の単位図により示されるように、カルマンフィルターが同定時に雨量の足りない分を 補っている事を示している。従って、レーダ定数のうちBは線形であるからある程度フィルタリングによって調 整することが可能であると考えられる。 


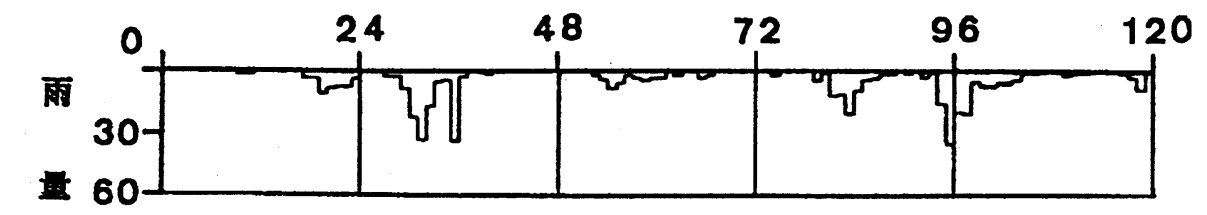

(mm/hr)

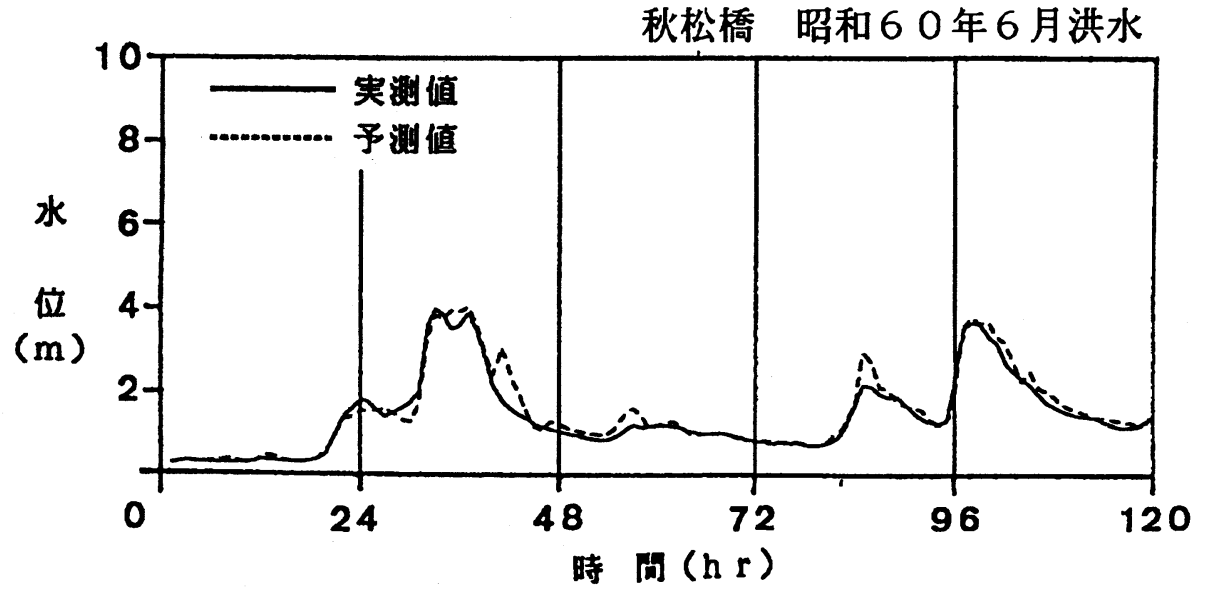

目3地上雨量および水位の計算值と実測値

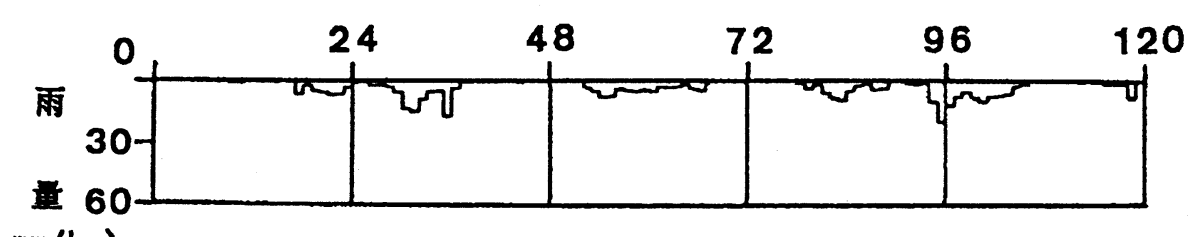

$\mathrm{mm} / \mathrm{hr}$ )

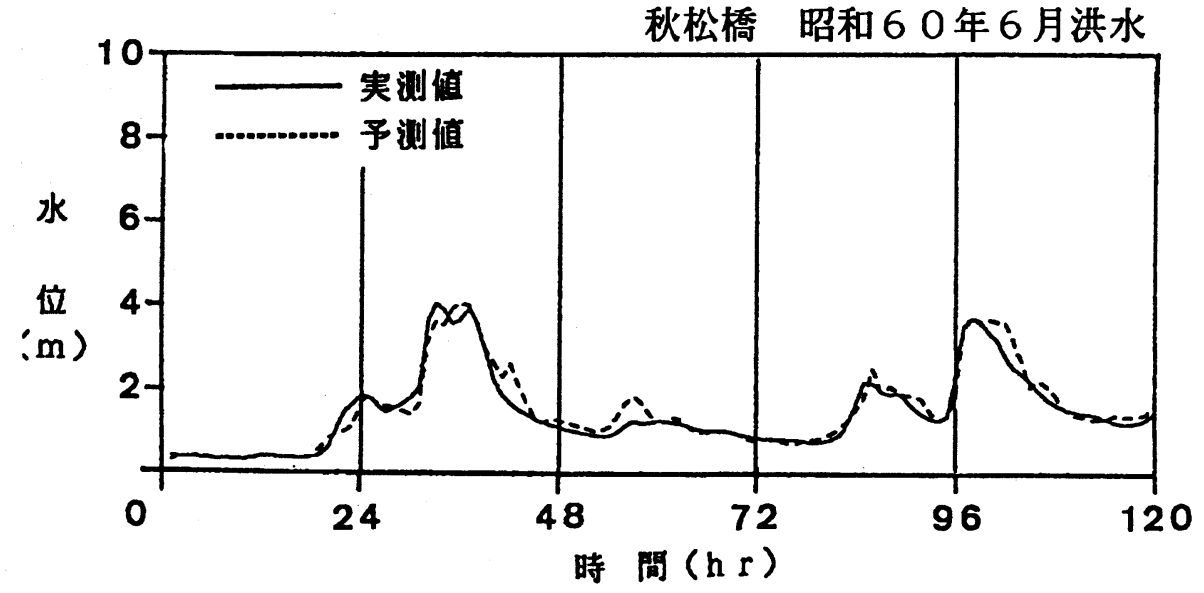

目4 レーダ雨量および水位の計算値と実測值 


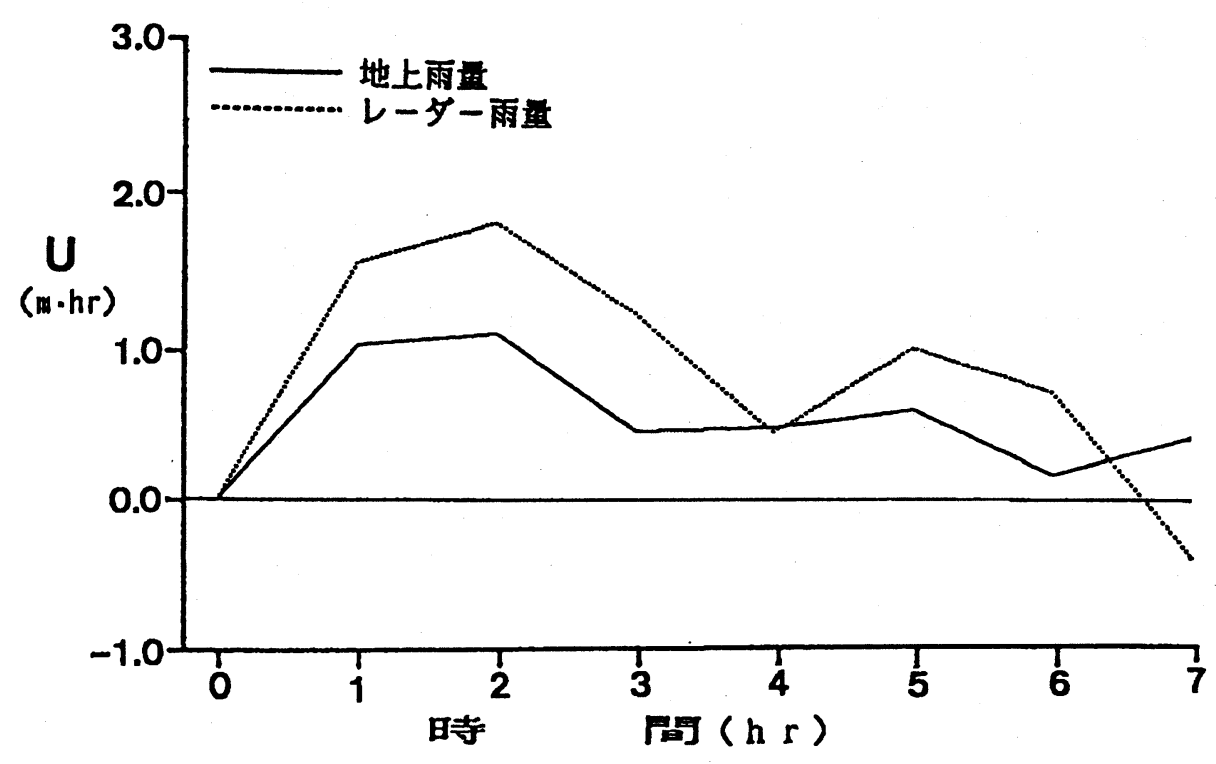

図5.同定単位図

次に実祭の洪水予測と同しように現時点までの降雨を使い、地上雨量計あるいはレーダ雨量計のデー夕を用い る埸合について計其してみた。その一例を目6及び区7に示す。因6は地上雨量計を、目7はレータ雨量計を用

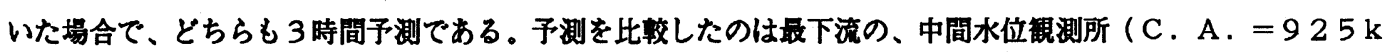
$\mathrm{m}^{2}$ ) である。この程度の流域面積に対しては、どちらの予測結果も良好な精度である事がわかる。

5. 結諭

レーダ雨量計を用いた本手法による洪水位予測は、レーダ定数 $\mathrm{B}$ を単位国に含めることにより。雨量データの

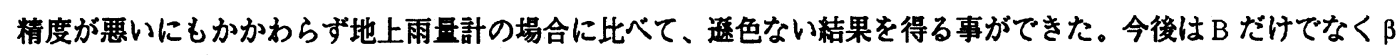
の補正を必要とする場合について検即する必要があろう。

辞辞

本論文を作成するにあたつて資料収藮について多大の御協力を頂いた建設省九州地方建設局遠賀川工事事務所調 查課長小林正典氏にこの場をお借りして厚くお礼を申し上げます。

\section{参考文献}

1)平野・森山・山下 · 中山；決水位の短時間予測に関する研究，土木学会第31回水理講演会論文集 1988.2

2)Hirano,M.Moriyama,T.Matsuki,M.,Nakayama,H.and Matsuo,K. (1986), "Real-Time Fofecasting for Water Stages of A Flash Flood",Proceedings,5th Int'l Cong.APD of IAHR,Souel,Vol.4,pp.269-282 


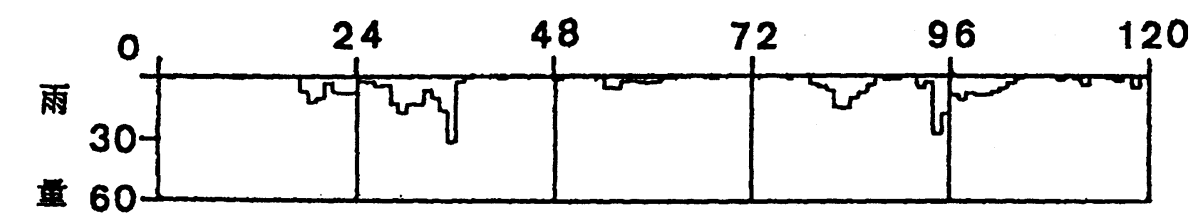

( $m m / h r)$

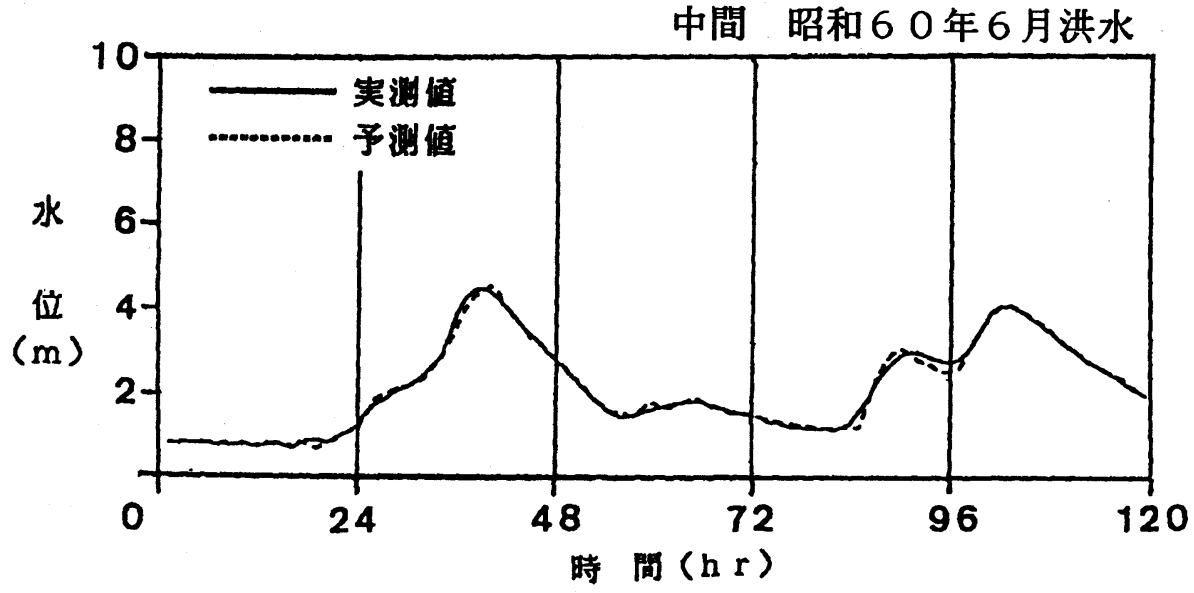

図6.地上雨量および水位の 3 時間予測值と実測值

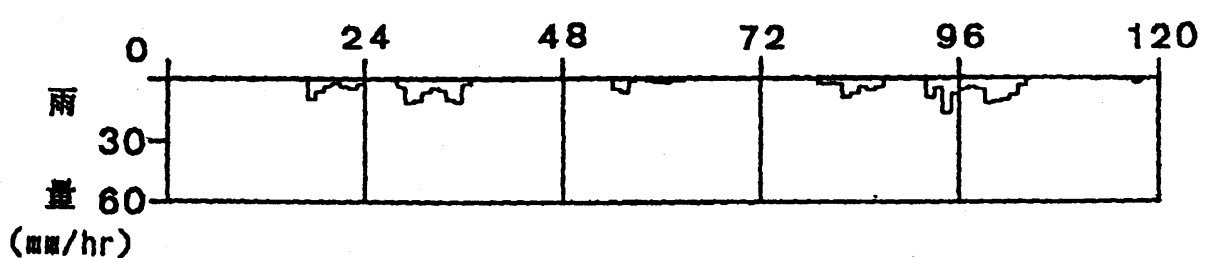

$(\mathrm{mm} / \mathrm{hr}$ )

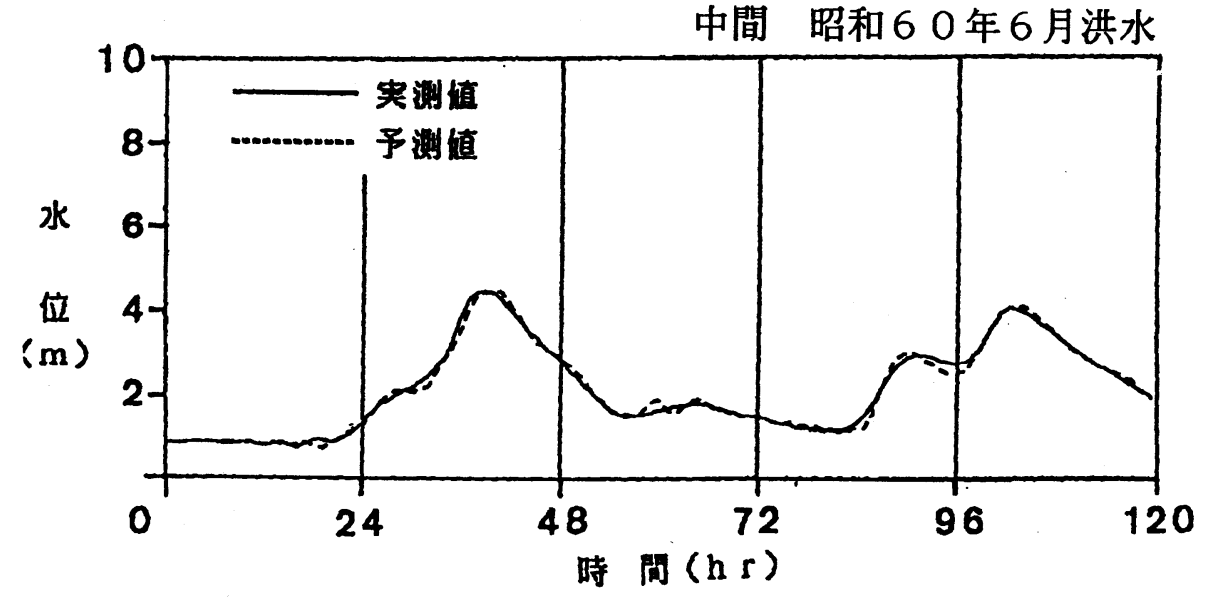

目 7 .レーダ雨量および水位の 3 時間予測值と実測值 